\title{
Children Processing Music: Electric Brain Responses Reveal Musical Competence and Gender Differences
}

\author{
Stefan Koelsch ${ }^{1,2}$, Tobias Grossmann ${ }^{1}$, Thomas C. Gunter ${ }^{1}$, \\ Anja Hahne ${ }^{1}$, Erich Schröger ${ }^{3}$, and Angela D. Friederici ${ }^{1}$
}

\begin{abstract}
Numerous studies investigated physiological correlates of the processing of musical information in adults. How these correlates develop during childhood is poorly understood. In the present study, we measured event-related electric brain potentials elicited in 5- and 9-year-old children while they listened to (major-minor tonal) music. Stimuli were chord sequences, infrequently containing harmonically inappropriate chords. Our results demonstrate that the degree of (in)appropriateness of the chords modified the brain responses in both groups according to music-theoretical principles. This suggests that already 5-year-old children process music according to a well-established cognitive representation of the major-minor tonal system and accord-
\end{abstract}

\section{INTRODUCTION}

Over the past decade, research activities on the neural correlates of music perception and performance expanded enormously (Zatorre \& Peretz, 2001). One reason is that music has been proven as a valuable tool for the investigation of the functional organization of the human brain (e.g., with respect to the processing of complex regularity-based and meaningful auditory information).

Recent studies of our group using event-related electric brain potentials (ERPs), event-related magnetic fields (EMFs), and functional magnetic resonance brain imaging (fMRI) revealed that adults process harmonic incongruities within a major-minor tonal context surprisingly well corresponding to the theory of harmony, even when they have not received formal musical training (Koelsch et al., 2001; Koelsch, Gunter, et al., 2002; Koelsch, Schmidt, \& Kansok, 2002; Koelsch, Schröger, \& Gunter, 2002; Maess, Koelsch, Gunter, \& Friederici, 2001; Koelsch, Gunter, Friedereci, \& Schröger, 2000). In these studies, chord sequences were presented to the participants, each sequence consisting of five chords (Figure 1). When consisting of in-key chords only (i.e., when all chords belong to

\footnotetext{
${ }^{1}$ Max-Planck-Institute of Cognitive Neuroscience, ${ }^{2}$ Harvard Medical School, ${ }^{3}$ Institute of General Psychology, Leipzig
}

ing to music-syntactic regularities. Moreover, we show that, in contrast to adults, an early negative brain response was left predominant in boys, whereas it was bilateral in girls, indicating a gender difference in children processing music, and revealing that children process music with a hemispheric weighting different from that of adults. Because children process, in contrast to adults, music in the same hemispheres as they process language, results indicate that children process music and language more similarly than adults. This finding might support the notion of a common origin of music and language in the human brain, and concurs with findings that demonstrate the importance of musical features of speech for the acquisition of language. the same key, for example, $\mathrm{C}$ major), the sequences built up a musical context towards the fifth chord. During such a sequence, listeners establish a notion of the prevailing key, and they develop strong expectancies for tonally related and harmonically appropriate chords to follow (Bigand \& Pineau, 1997; Bigand, Madurell, Tillmann, \& Pineau, 1999; Tillmann, Bigand, \& Pineau, 1998; Bharucha \& Krumhansl, 1983; Bharucha \& Stoeckig, 1987; Krumhansl, Bharucha, \& Kessler, 1982; Krumhansl \& Kessler, 1982; see also Huron \& Parncutt, 1993). Infrequently, however, a harmonically inappropriate "Neapolitan sixth chord" was presented at either the third or the fifth position of the sequence (Figure 1B and C). Such a Neapolitan chord is a subdominant variation and contains out-of-key notes with respect to a prevailing major key. The Neapolitan chords elicit two distinct electric brain responses: an early right anterior negativity (ERAN), which has an amplitude maximum around $200 \mathrm{msec}$ after the onset of the chord, and a late bilateral negativity (N5, which is maximal around 500-550 msec, Koelsch, Gunter, et al., 2000; Koelsch et al., 2001; Koelsch, Schmidt, et al., 2002; Koelsch, Schröger, et al., 2002).

It is important to note that Neapolitans at the third position differed with respect to their harmonic appropriateness from Neapolitans at the fifth position (physically, Neapolitans at the third did not differ from those 


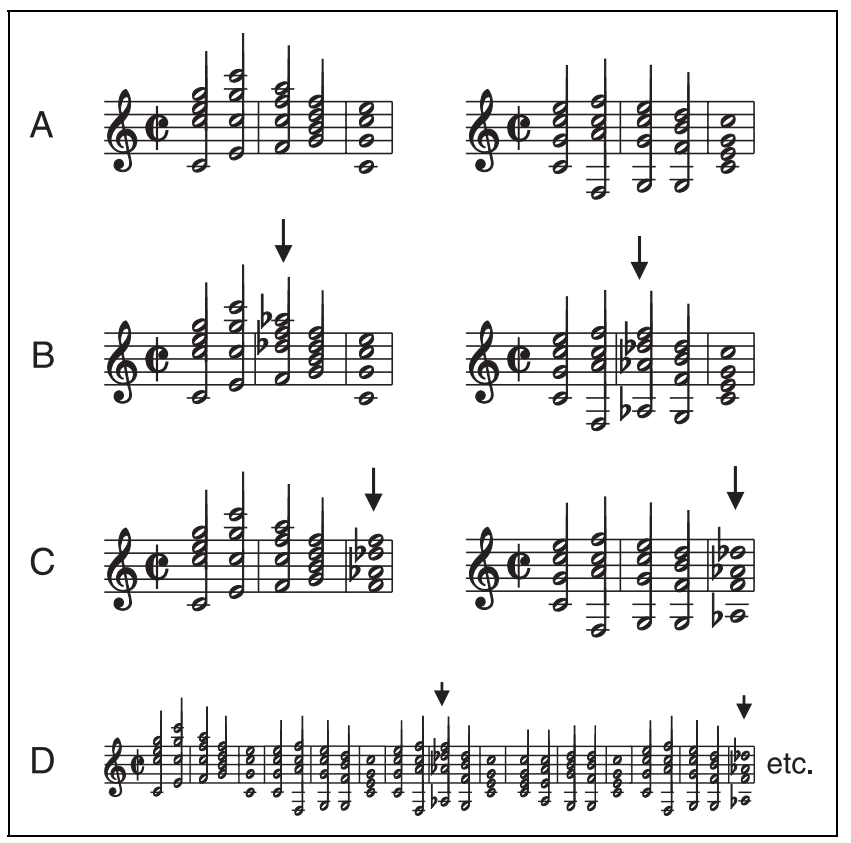

Figure 1. Examples of chord sequences. (A) Consisting of in-key chords only; (B) Containing a Neapolitan chord at the third position; and (C) Containing a Neapolitan at the fifth position. (D) Sequences in direct succession as presented in the experiment (from Maess et al., 2001).

at the fifth position; see also Koelsch, Schröger, et al., 2002): Neapolitans at the third position are only to a small degree harmonically inappropriate (because the musical context was not yet clearly established, and because a subdominant was appropriate at the third position), whereas Neapolitans at the end of the sequences clearly violate the harmonic expectancies of listeners (because the musical context is fairly well established, and because a subdominant is false at that position). Correspondingly, both ERAN and N5 are considerably larger in amplitude when elicited by Neapolitans at the fifth compared to the third position.

Note that the processing of auditory oddballs without a complex regularity-based (e.g., major-minor tonal) context does not lead to an amplitude difference of potentials elicited at the third compared to the fifth position (Koelsch et al., 2001), indicating that the generation of the ERAN (and subsequent later negativities) is rather music-specific. The ERAN is taken to reflect the violation of a musical sound expectancy, the musical expectancies are most presumably established with reference to a complex system of regularities (in the mentioned experiments: regularities of major-minor tonal, or "classical" Western European, music). As this system has also been taken as part of a musical syntax (Maess et al., 2001; Tillmann, Bharucha, \& Madurell, 2000; Patel, Gibson, Ratner, Besson, \& Holcomb, 1998; Swain, 1997; Sloboda, 1985; Deliège, 1984), the ERAN may be interpreted as a correlate of music-syntactic processing (Koelsch et al., 2001; Koelsch, Schmidt, et al., 2002; Maess et al., 2001). Interestingly, the ERAN is generated in Broca's area and its right hemisphere homotope (Maess et al., 2001), that is, in areas which are also involved in the syntactic analysis of speech.

The ERAN resembles the early left anterior negativity (ELAN), which reflects the processing of syntactic aspects of language (phrase structure violations; Friederici, 1998, 2002; Hahne \& Friederici, 1999). The ELAN is, like the ERAN, at least partly generated in Broca's area and its right hemisphere homotype (although generators located in the anterior superior temporal gyrus also contribute to the ELAN; Friederici, Wang, Herrmann, Maess, \& Oertel, 2000).

The ERAN can be elicited preattentively (Koelsch, Schröger, et al., 2002), reflecting that musical expectancies are automatically generated during the perception of a musical context (Bharucha \& Krumhansl, 1983; Bharucha \& Stoeckig, 1986, 1987; Krumhansl \& Kessler, 1982). Moreover, the ERAN is larger in subjects with extensive formal musical training ("musicians") than in those without formal musical training ("nonmusicians"; Koelsch, Schmidt, et al., 2002), reflecting that more specific representations of musical regularities lead to more specific musical expectancies. Recently, it was found that the scalp distribution of the ERAN differs between genders, men showing a right hemispheric predominance and women showing a fairly bilateral distribution of this effect (Koelsch, Maess, Grossmann, $\&$ Friederici, 2002).

Up to now several studies showed that the ERAN shares a number of features with the mismatch negativity (MMN; Schröger, 1998; Näätänen, 1992). The most important similarities are time-course, polarity, scalp distribution, automaticity (both ERAN and MMN can be elicited preattentively; Koelsch, Schröger, et al., 2002), and the sensitivity to auditory stimuli that do not match with a previously presented group of events (Koelsch, Gunter, et al., 2000; Koelsch, Maess, et al., 2002; Koelsch, Schmidt, et al., 2002). Because of the similarities between ERAN and MMN, and because the ERAN—in contrast to the "classical" MMN—specifically correlates with the processing of complex musical regularities (Koelsch et al., 2001), it has been suggested that the ERAN may be understood as a "music-syntactic MMN" (Koelsch, Maess, et al., 2002; Koelsch, Schmidt, et al., 2002).

The ERAN is usually followed by a late negativity (N5). The N5 is taken to reflect processes of harmonic integration that follow the detection of a harmonically inappropriate musical event (Koelsch, Gunter, et al., 2000).

Previous ERP studies investigating music perception have only been conducted with adults. It is thus an open question how the neural correlates reflecting music processing develop during childhood. The present study investigates this issue in children aged 5 and 9 years, using an experimental protocol which is very similar to previous EEG and MEG studies with adults (Koelsch, Gunter, et al., 2000; Koelsch, Gunter, et al., 2001; 
Koelsch, Schmidt, et al., 2002; Koelsch, Schröger, et al., 2002; Maess et al., 2001). We found differences between the ERPs elicited by the harmonically appropriate chords and the harmonically unrelated Neapolitan chords, indicating that the children processed the chords according to their harmonic appropriateness, that is, according to a cognitive representation of the major-minor tonal system. Moreover, clear amplitude differences of effects elicited by Neapolitans at the fifth compared to the third position were observed, indicating that children processed the Neapolitans with respect of their musicsyntactic (in)appropriateness, because Neapolitans at the fifth position are music-syntactically more inappropriate than at the third position (see above). Whereas the early negativity elicited by Neapolitan chords shows a clear right hemispheric preponderance in adult men (the ERAN), this effect was lateralized to the left in boys (in girls, this effect was bilateral, as it is in adult women). The skillful processing of the music concurs with a substantial body of evidence which suggests that a sophisticated processing of musical elements of speech is of considerable importance for the acquisition of language (Trehub, Schellenberg, \& Hill, 2000; Papoušek, 1996; Jusczyk et al., 1992; Jusczyk \& Krumhansl, 1993; Trainor \& Trehub, 1992; Krumhansl \& Jusczyk, 1990; Fernald, 1989).

\section{RESULTS}

Figure 2 shows the ERPs elicited at the fifth position of the chord sequences, separately for 5- and 9-year-old children. The Neapolitan chords elicited in both groups an early anterior negativity which emerged around $200 \mathrm{msec}$ after the onset of the chord and reached its maximum at Fz around $320 \mathrm{msec}$ (F3: $328 \mathrm{msec}, \mathrm{F} 4: 352 \mathrm{msec}$ ). The early negativity was followed by a late tonic negativity which emerged around $400 \mathrm{msec}$ and peaked in both groups around $550 \mathrm{msec}$. The amplitude of the early negativity appears to be larger in the 9-year-old children (this difference between 9- and 5-year-olds was statistically not significant), the later negativity did virtually not differ between the two groups. An ANOVA with factors chord-type, lateralization, and age for the early negativity (280-430 msec) revealed an effect of chord-type, $F(1,26)=19.68, p<.0001$, no two- or three-way interactions. An analogous ANOVA for the late negativity (500$700 \mathrm{msec})$ revealed an effect of chord-type, $F(1,26)=$ $37.18, p<.0001$, no two- or three-way interactions.

Figure 3 shows the ERPs elicited at the fifth position separately for boys and girls. Whereas the early negativity had a left hemispheric predominance in boys, it was bilaterally distributed in girls. The late negativity was bilateral in both groups. An ANOVA with factors chordtype, lateralization, and gender for a time window from 280 to $430 \mathrm{msec}$ revealed a marginal interaction between the three factors, $F(1,26)=38, p<.09$. ANOVAs with factors chord-type and lateralization, conducted sepa-

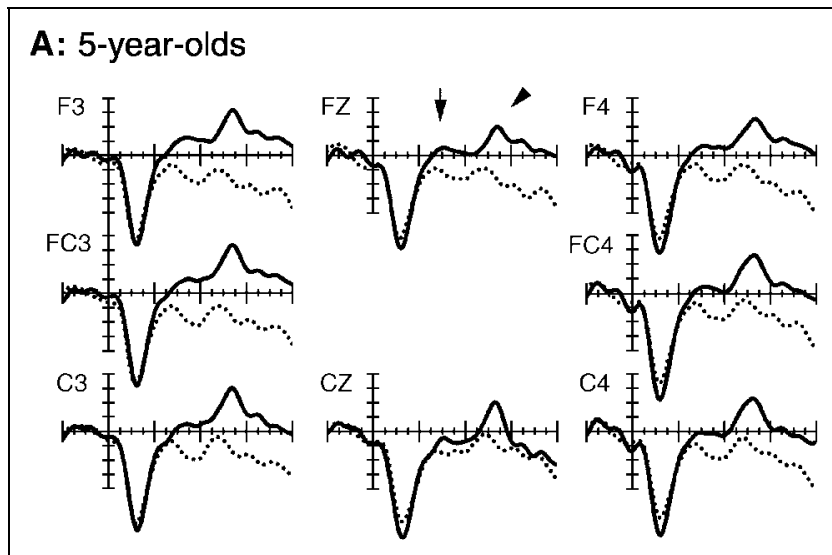

B: 9-year-olds

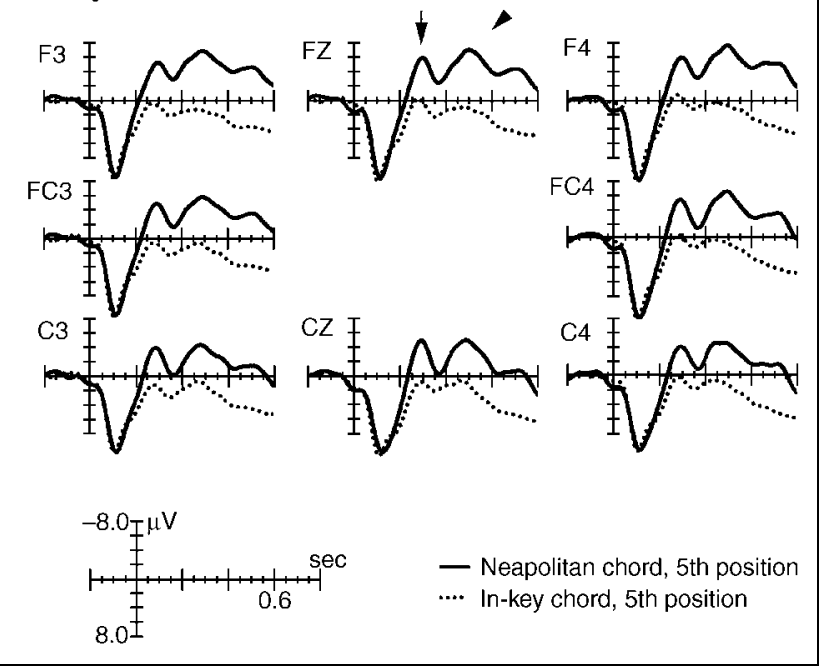

Figure 2. Grand-average ERPs elicited at the fifth position of the chord sequences, separately for 5-year-olds (A) and 9-year-olds (B). In both age groups, the harmonically inappropriate Neapolitan chords elicited an early negativity (long arrow) which was followed by a late negativity (short arrow).

rately for boys and girls, revealed for both boys and girls effects of chord-type (with $p<.007$ in each analysis), but an interaction between the two factors was indicated only for the boys, $F(1,13)=10.9, p<.006$, indicating that the early negativity was lateralized in boys (i.e., no interaction was found for the girls, $p>.90$ ).

When the Neapolitan chords were presented at the third position of the chord sequences, no ERP effects were elicited compared to in-key chords (Figure 4). Comparing the ERPs of all children elicited at the third and fifth position, an ANOVA for the early time window (280-430 msec) with factors chord-type and position revealed an effect of chord-type, $F(1,26)=$ 8.03, $p<.01$, and an interaction between the two factors, $F(1,26)=16.35, p<.0005$, indicating that the ERP effects of Neapolitans clearly differed between the third and fifth positions. Similarly, the analogous ANOVA for the late time window (500-700 msec) revealed an effect of chord-type, $F(1,26)=27.48$, 


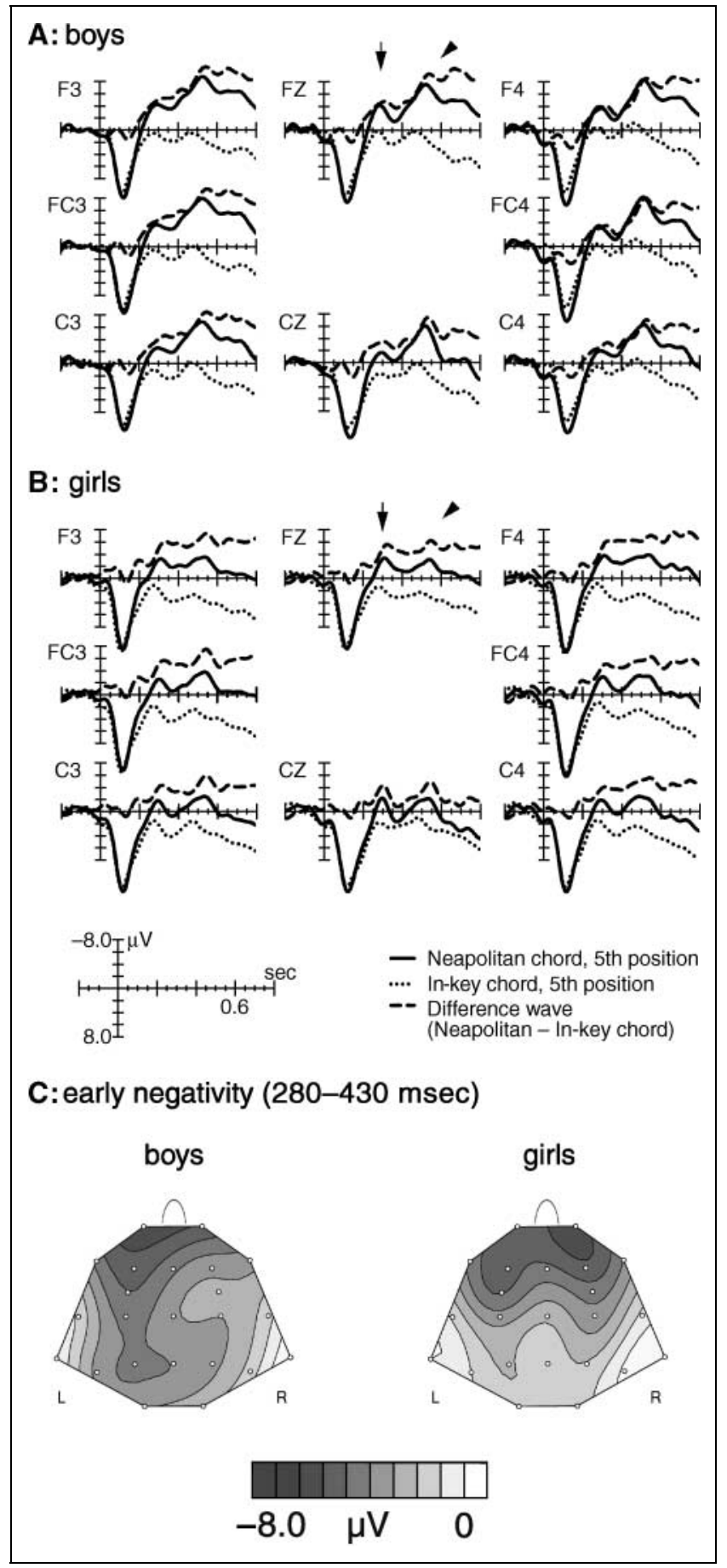

Figure 3. Grand-average ERPs elicited at the fifth position of the chord sequences, separately for boys (A) and girls (B). The early negativity (long arrow) was lateralized in boys, but not in girls. The late negativity (short arrow) was bilateral in both groups. (C) Potential maps of the early negative effect, showing the left hemispheric weighting in boys, and the fairly bilateral distribution in girls (difference ERPs: in-key subtracted from Neapolitan chords, interpolated over a time window from 280 to $430 \mathrm{msec}$, view from top, nose is upwards).

$p<.0001$ and an interaction between the two factors, $F(1,26)=18.87, p<.0002$. ANOVAs for the same time windows for chords at the third position only (with factors chord-type, lateralization, and age) did not reveal any effect or interaction ( $p$ values for chordtype: $p>.89$ for the early, and $p>.79$ for the late time window).

\section{DISCUSSION}

\section{Harmonic Incongruities}

Neapolitan chords presented at the fifth position elicited distinct ERP effects in both 5- and 9-year-old children (Figure 2). Similar to adults (Koelsch, Gunter, et al., 2000; Koelsch et al., 2001; Koelsch, Schmidt, et al. 2002; Koelsch, Schröger, et al., 2002), two anterior negativities were observed: an earlier negativity (the ERAN, or "music-syntactic MMN"), which had an amplitude peak around $320 \mathrm{msec}$, and a later negativity (the N5, maximal around $550 \mathrm{msec}$ ).

The finding that in both age groups the ERPs of Neapolitans differed from those elicited by harmonically related chords indicates that already the 5-year-old children processed the chords according to their harmonic relatedness. As noted in the Introduction, Neapolitans (in $\mathrm{C}$ major: $\mathrm{f}$, a flat, $\mathrm{d}$ flat) are less related to the preceding musical context than tonic chords (in $\mathrm{C}$ major: c, e, g). In the circle of fifths, the (major) triad $\mathrm{d}$ flat, $\mathrm{f}$, a flat is five-fifths distant from the major triad c, e, g (Patel et al., 1998; Krumhansl \& Kessler, 1982). A substantial body of evidence indicates that harmonically unrelated chords are perceived as less appropriate, or expected, compared to related chords (Bigand \& Pineau, 1997; Bigand et al., 1999; Tillmann, Bigand, \& Pineau, 1998; Bharucha \& Krumhansl, 1983; Bharucha \& Stoeckig, 1987; Krumhansl et al., 1982; Krumhansl \& Kessler, 1982), even in musical novices (Bigand \&

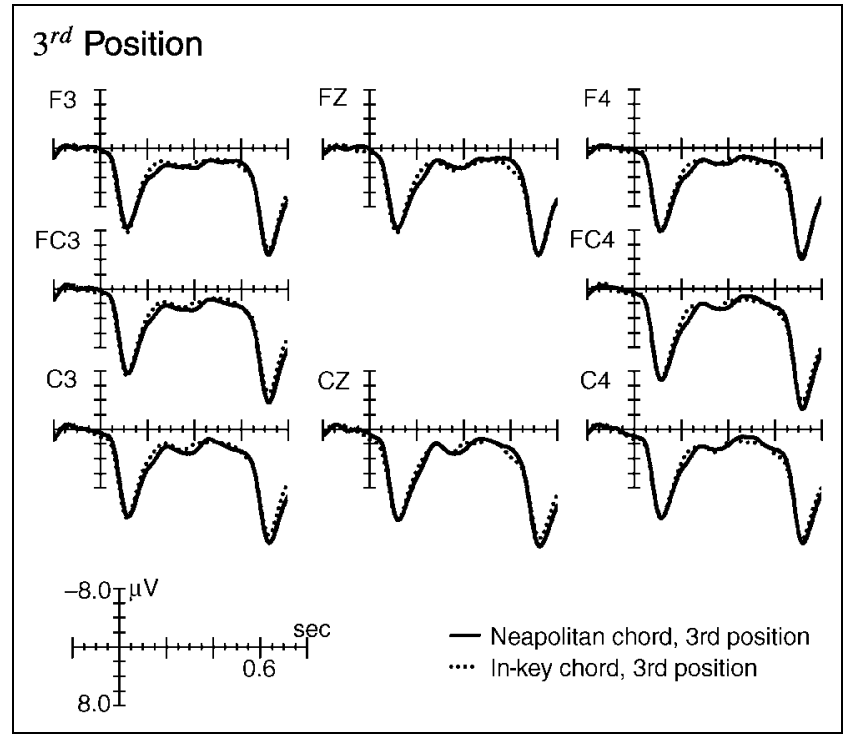

Figure 4. Grand-average ERPs elicited at the third position of the chord sequences (pooled data from 5-and 9-year-olds). No effect is observable between the Neapolitan chords and the in-key chords at a position at which the Neapolitans are music-syntactically fairly appropriate. 
Pineau, 1997; Bigand et al., 1999; Bigand, Tillmann, Poulin, Adamo, \& Madurell, 2001; Maess et al., 2001; Regnault, Bigand, \& Besson, 2001; Koelsch, Gunter, et al., 2000; Tillmann, Bigand, \& Madurell, 1998). Because the harmonic relatedness of chords refers to the harmonic principles of the major-minor tonal system (which are described by music theory, e.g., Schönberg, 1969), the present finding suggests that already 5-year-old children process music according to a well-established cognitive representation of this musical system.

\section{Effects of Position}

No effects were elicited by the Neapolitans at the third position in children (Figure 4), in contrast to adults, where Neapolitans at the third position usually elicit significant effects. In adults, importantly, the effects elicited at the third position are always considerably smaller than at the fifth position (Koelsch, Gunter, et al., 2000; Koelsch et al., 2001; Koelsch, Schröger, et al., 2002). Note that the Neapolitans presented at the third position were on average physically identical compared to those at the fifth position. Moreover, the Neapolitans at the third position did not share more component tones (or overtones) (Parncutt, 1989; Schmuckler, 1989) with the preceding chords than Neapolitan chords at the fifth position, hence the degree of "sensory dissonance" of chords was balanced between the third and fifth positions (Koelsch et al., 2001; Koelsch, Schmidt, et al., 2002, but see also below). It is the musical context, which is (from a music-theoretical point of view) more specified at the end (i.e., at the fifth position) compared to the middle (i.e., at the third position) of the sequence. Moreover, Neapolitans at the third position were relatively suitable in respect of their chord function (because they are a subdominant variation and commonly used as predominant chord), but false at the fifth position (because only a tonic chord was appropriate at that position). The finding that, in contrast to adults, no effect was observed in response to Neapolitans at the third position might be explained by the assumption that children are (although musically competent) less sensitive to musical violations than adults, because children might have less specific representations of musical regularities than adults (Koelsch, Schmidt, et al., 2002). That is, children might accept a Neapolitan as a subdominant substitute at the third position as harmonically appropriate.

The finding that the Neapolitans elicited in children distinct responses at the fifth, but not at the third, position, indicates that children processed the Neapolitan chords according to regularities of "classical" major-minor tonal music, which are described by the theory of harmony (Piston, 1987, but see also below). As these regularities have previously been denoted as part of a musical syntax (Koelsch, Schmidt, et al., 2002; Maess et al., 2001; Tillmann et al., 2000; Patel et al., 1998; Swain, 1997; Sloboda, 1985; Deliège, 1984), the present findings suggest that already 5- and 9-year- old children have an (implicit) knowledge about musical syntax (i.e., of the complex regularities of tonal music).

Because children had no special musical expertise, the present findings allow a broad generalization, namely, that the acquisition of knowledge about musical regularities, and the processing of musical information according to this knowledge is a general ability of the human brain, which is already present at the age of 5 . At this age, children participating in this study had been exposed in everyday life to major-minor tonal music, that is, to the regularities underlying the music of their culture. Thus, it is highly likely that this knowledge was acquired due to the normal exposure to major-minor tonal music (i.e., without receiving special musical training; Tillmann et al., 2000). Further experiments have to clarify at which age this knowledge is acquired, and to which degree it is dependent on culture-specific musical experiences at an early age.

\section{Comparison to the "Classical" MMN}

It is important to note that the presence of the early anterior negativity at the fifth position and the absence of this effect at the third position indicate that the chords were processed according to complex musical regularities: If the effects observed would merely reflect a frequency MMN elicited by the out-of-key notes of the Neapolitans (which were, in contrast to the notes of the in-key chords, not contained in the preceding chords), then the effects should have been observed also at the third position (Koelsch et al., 2001). Also note that the physical MMN has a shorter latency that the ERAN, in both adults (Koelsch et al., 2001) and school-age children (Cheour, Leppänen, \& Kraus, 2000; Kraus et al., 1992). That is, the early negativity elicited in the children was not mainly a "classical" frequency MMN (Cheour et al., 2000; Gomot, Gard, Roux, Barthelemy, \& Bruneau, 2000; Schröger, 1998; Näätänen, 1992), but was rather due to a processing that referred to a representation of complex musical regularities (in the present study, regularities of major-minor tonal music). However, the present data do not allow to exclude that there is also partly a frequency MMN contribution in the signal, which might be larger at the fifth than at the third position. Thus, the question of whether the ERAN effect is entirely cognitive or also partly sensory remains to be specified (see also Parncutt \& Bregman, 2000).

\section{Task Relevancy}

It is surprising to note that the described effects were present although the Neapolitans were task-irrelevant (the deviant instruments were task-relevant and the 
harmonic dimension of the musical stimulus had to be ignored). The absence of a P300 indicates that the children indeed ignored the harmonies (while concentrating on the timbre of the musical stimulus), since the detection of a target generally elicits a P300, in adults as well as in children (Kilpelainen, Koistinen, Kononen, Herrgard, \& Partanen, 1999; Fuchigami, Okubo, Fujita, \& Okuni, 1993; Curry \& Polich, 1992). Thus, the present findings might suggest that children process harmonic relations and musical syntax fairly automatic (i.e., even when they do not specifically attend harmonies). This finding concurs with the finding that the ERAN can be elicited preattentively in adults (Koelsch, Schröger, et al., 2002), and thus reflects a fairly automatic musical processing.

\section{Gender Differences}

An interesting finding is that boys showed a lateralization of the early anterior negativity to the left hemisphere, whereas this effect was bilateral in girls. In adults, the ERAN has recently been shown to have a clear right hemispheric preponderance in men, but a rather bilateral distribution in women (Koelsch, Maess, et al., 2002). The finding that the early negativity is lateralized to the right in men, but lateralized to the left in boys, indicates that the lateralization of this ERP effect alters as a developmental effect; the significance and the details of this effect remain to be specified (but see also below).

That is, children processed the music-syntactic information (as indexed by the early negativity) with considerable aid of the left hemisphere (boys relying more strongly on the left hemisphere than girls). Importantly, the early negativity has been shown to be generated in the inferior fronto-lateral cortex (Maess et al., 2001). In adults, this region is also involved in the processing of syntactic aspects of language (Caplan, Alpert, Waters, \& Olivieri, 2000; Friederici, Meyer, \& von Cramon, 2000; Friederici et al., 2000; Caplan, Alpert, \& Waters, 1999; Dapretto \& Bookheimer, 1999), and several studies report a strong left hemisphere advantage for syntactic language processing in children (Dennis \& Kohn, 1975; Dennis \& Whitaker, 1976; Dennis, 1980). Notably, both functional (Kansaku, Yamaura, \& Kitazawa, 2000; Jaeger et al., 1998; Pugh et al., 1996; Shaywitz et al., 1995) and anatomical gender differences (Amunts et al., 1999; Harasty, Double, Halliday, Kril, \& McRitchie, 1997) have been reported for this region in adults, indicating (first) that language functions in this region are stronger leftlateralized in men than in women (who show a fairly bilateral pattern; Jaeger et al., 1998; Pugh et al., 1996; Shaywitz et al., 1995), (second) that the cell density in this region shows a greater hemispheric asymmetry in men than in women (men showing a lower cell density in the right hemisphere; Amunts et al., 1999), and (third) that this region is proportionally smaller in the male than in the female brain (Harasty et al., 1997). Assuming that the early negativity in children was generated in the same brain structure as the early negativity in adults (i.e., in the inferior fronto-lateral cortex), the present data concur with previous findings which indicate gender differences for this area of the brain.

Moreover, the present gender difference can be related to findings of gender differences in the hemispheric weighting of auditory functions. Greater left hemisphere control of verbal functions in men than in women has also been reported in lesion studies (McGlone, 1980; Inglis \& Lawson, 1881), and for posterior language areas in functional imaging studies (Phillips, Lowe, Dzemidzic, \& Mathews, 2001; Kansaku et al., 2000). In children, differences between boys and girls have also been observed in dichotic listening paradigms between the ages of 6 and 9, boys displaying less accuracy for the left ear compared to girls (Moulden \& Persinger, 2000; Gaillard, Converso, \& Ben Ammar, 1988). Moreover, the prevalence of several language disorders in boys relative to girls, and the finding that women have a facilitated language and verbal learning (Kramer, Delis, \& Daniel, 1988; Kramer, Delis, Kaplan, O'Donnell, \& Prifitera, 1997; Ekstrand, 1980) have been taken to reflect the greater asymmetry of language functions in the male than in the female brain (Kimura, 1999; Allen \& Gorski, 1991; McGlone, 1980; Hier, 1979). Finally, fiber tracts like the corpus callosum and the anterior commissure, which connect the two hemispheres, have a larger size in females (Steinmetz, Staiger, Schlaug, Huang, \& Jancke, 1995; Allen \& Gorski, 1991; deLacoste Utamsing \& Holloway, 1982), presumably underlying the functional gender differences in the lateralization of cognitive functions such as language (Kimura, 1999; Steinmetz et al., 1995; Allen \& Gorski, 1991; deLacoste Utamsing \& Holloway, 1982).

\section{Music and Language}

In combination with the previously mentioned data, the present data indicate that boys between the age of 5 and 10 years process syntactic aspects of both music and language predominantly in the same hemisphere (i.e., in the left hemisphere), and that girls process music more bilaterally, as they process language. This finding might support the notion of a common origin of music and language in the human brain (Wallin, Merker, \& Brown, 2000), concurrent with the literature indicating considerable overlap of neural structures and processes underlying the perception of music and language (Koelsch, Gunter, et al., 2000; Koelsch, Maess, \& Friederici, 2000; Koelsch, Gunter, et al., 2002; Maess et al., 2001; Wallin et al., 2000; Liegeois-Chauvel, Peretz, Babaie, Laguitton, \& Chauvel, 1998; Patel et al., 1998; Platel et al., 1997; Peretz, Kolinsky, Tramo, \& Labrecque, 1994; Zatorre, Evans, \& Meyer, 1994). Moreover, the notion of a common origin of music and language in the brain 
corresponds with the observation that musical elements of speech play an important role for the acquisition of language: It has been hypothesized that music and speech are intimately connected in early life (Trehub et al., 2000; Trainor \& Trehub, 1992), that musical elements pave the way to linguistic capacities earlier than phonetic elements (Papoušek, 1996), and that melodic aspects of adult speech to infants represent the infant's earliest associations between sound patterns and meaning (Fernald, 1989), as well as between sound patterns and syntactic structure (Jusczyk et al., 1992; Jusczyk \& Krumhansl, 1993; Krumhansl \& Jusczyk, 1990).

As mentioned before, the present data indicate that the early anterior negativity changes its lateralization during further ontogenesis in boys (because this effect is lateralized to the right in men). These changes can be explained by a restriction of resources in the left hemisphere required for the processing of language (Woods \& Teuber, 1978), especially as the processing of language undergoes some functional changes around the age of 9-10: (a) around the age of 9 years, the fast and automatic processing of syntactic violations in language seems to be established: whereas 5-years-olds do not show an ELAN in response to phrase structure violations, an ELAN becomes observable around the age of 9 (unpublished data from A. Hahne \& A. D. Friederici); (b) children who became aphasic before the age of 8-9 years recover faster compared to children who become aphasic after the age of 8-9 (Woods \& Teuber, 1978); (c) aphasia in children under the age of 10 tends to be predominantly nonfluent in kind (independent of whether the lesion is left frontal or left temporal), presumably due to the fact that language is less automatic in children and therefore not yet installed as a procedural system in Broca's area (Friederici, 1994); and (d) children between the age of 5 and 10 years differ from adults in their on-line comprehension behavior; while adults process grammatical function words independent of semantic context, children up to the age of 10 do not (Friederici, 1983). Note that the anterior language region including Broca's area has been reported to undergo some kind of functional evolution with age (Basso, Bracci, Capitani, Laiacona, \& Zanobio, 1987; Basso \& Scarpa, 1990), and that this age-related effects might, for instance, be related to the myelination of the cerebral commissures, which achieves near-adult characteristics after 9 years of age (Moulden \& Persinger, 2000). Moreover, the restriction of language resources in Broca's area is presumably more critical for men than for women, because this area is proportionally smaller in men than in women (Harasty et al., 1997), and because the cell density in this area is lower in the right hemisphere of men (Amunts et al., 1999). The restriction of language resources might lead to the pronounced change of lateralization of music-syntactic processing from the left hemisphere in boys to the right hemisphere in men.
Note that children between the age of 5 and 9 show electrical reflections of relatively fast and automatic music-syntactic processing (as indexed by the early negativity), but not fast and automatic language-syntactic processing (as indexed, e.g., by the ELAN). Thus, the present data indicate that children show a fast processing of syntax in music before in language, supporting the notion that musical elements of speech (such as prosody) play a crucial role for the infant's earliest associations between sound patterns and syntactic structure (Jusczyk et al., 1992; Jusczyk \& Krumhansl, 1993; Krumhansl \& Jusczyk, 1990), and thus for the acquisition of language (Trehub et al., 2000; Papoušek, 1996; Jusczyk et al., 1992; Jusczyk \& Krumhansl, 1993; Trainor \& Trehub, 1992; Krumhansl \& Jusczyk, 1990; Fernald, 1989).

\section{Conclusion}

The present study demonstrates that already 5-year-old children process music according to a well-established cognitive representation of complex musical regularities, or musical syntax. Whether the effects reflect entirely cognitive or also partly sensory processes remains to be specified. Interestingly, the electrical correlates of this music-syntactic processing are observable at an earlier age than those of syntactic language processing, supporting the notion that musical elements of speech play a crucial role for the acquisition of language (Trehub et al., 2000; Papoušek, 1996; Jusczyk et al., 1992; Jusczyk \& Krumhansl, 1993; Trainor \& Trehub, 1992; Krumhansl \& Jusczyk, 1990; Fernald, 1989). The Neapolitan chords at the third position elicited no effect, in contrast to adults (in which these chords elicit small but significant effects), suggesting that children have less specific representations of musical regularities than adults. The music-syntactic processing was left-lateralized in boys, indicating that boys process aspects of both language and music predominantly in the same hemisphere, that is, in the left hemisphere, in contrast to girls who process both music and language more bilaterally. This finding might suggest a common origin of music and language in the human brain, contributing to the literature which indicates considerable overlap of neural structures and processes underlying the perception of music and language (Koelsch, Gunter, et al., 2000; Koelsch, Maess, et al., 2000; Koelsch, Gunter, et al., 2002; Maess et al., 2001; Wallin et al., 2000; Liegeois-Chauvel et al., 1998; Patel et al., 1998; Platel et al., 1997; Peretz et al., 1994; Zatorre et al., 1994). Because children had no special musical expertise, the present findings allow a broad generalization, namely, that the acquisition of (implicit) knowledge about musical regularities and the relatively fast and automatic processing of musical information according to this knowledge is a general ability of the human brain (Koelsch, Gunter, et al., 2000; Koelsch, 
Gunter, et al., 2002; Maess et al., 2001), which is present already at the age of 5 .

\section{METHODS}

\section{Subjects}

Two age groups of children were measured: 5-year-olds ( $n=14$, mean age 5.7, age range 4.11-5.11, 7 girls) and 9-year-olds ( $n=14$, mean age 9.6, age range 8.3-9.11, 7 girls). All children were right-handed, had normal hearing, and were healthy. Children had no formal musical training.

\section{Stimuli}

The experimental protocol was virtually identical (Koelsch, Gunter, et al., 2000; Koelsch, Schmidt, et al., 2002; Maess et al., 2001), or very similar (Koelsch et al., 2001; Koelsch, Schröger et al., 2002) to previous experiments. A pool of stimuli consisted of 128 different chord sequences. Each sequence consisted of five chords, texture and arrangement of chords followed the classical rules of harmony and part-writing (Hindemith, 1940). The first chord was always the tonic of the following chord sequence. Chords at the following positions were either in-key chords, or secondary dominants at the second position, a Neapolitan chord at the third position, or a Neapolitan chord at the fifth position. Chords at the fourth position were always dominant seventh chords. In-key chord sequences were terminated by a tonic chord. Secondary dominants were never followed by a Neapolitan chord at the third position. Neapolitan chords at the fifth position did not follow a Neapolitan chord at the third position. From the pool of 128 sequences, 252 chord sequences were randomly chosen in a way that $25 \%$ of the sequences contained a secondary dominant, 25\% a Neapolitan chord at the third position, and $25 \%$ a Neapolitan at the fifth position.

Most of the chords were played with a piano sound, in $8 \%$ of the chord sequences an in-key chord from positions 2 to 5 was played by an instrument other than piano (e.g., harpsichord, celesta, marimba). Presentation time of chords 1 to 4 was $600 \mathrm{msec}$ and chord 5 was presented for $1200 \mathrm{msec}$. Chords were presented via speakers and played under computerized control via MIDI on a synthesizer with approximately $60 \mathrm{~dB}$ SPL. The main key of the sequences was changed six times within the whole session, following the presentation of a cartoon (see below). Chord sequences were played in direct succession, with no pause or silent interval between chords or sequences, sounding like a musical piece (Figure 1D).

\section{Procedure}

Children were seated in a comfortable chair in front of a monitor and two loudspeakers. They were instructed to keep their eyes open and to avoid movements of their head and their eyes. During the presentation of the music, a smiley was presented in the center of the screen as a fixation point. The children were only informed about the deviant instruments, not about the Neapolitan chords. They were instructed to listen carefully to the sound of the music and to press a button immediately whenever they detected a deviant instrument. The harmonic appropriateness of chords was to be ignored. This task allowed to control whether the children actually listened to the musical stimulus. Note that the Neapolitans were task-irrelevant (in order to avoid an overlap of the effects elicited by the Neapolitans with effects elicited by detectional and decisional processes; Maess et al., 2001; Koelsch, Gunter, et al., 2000). Following a correct detection, an animated cartoon was presented on the screen. The duration of the experimental session was approximately $20 \mathrm{~min}$.

\section{Measurements and Data Analysis}

The EEG was recorded with $\mathrm{Ag}-\mathrm{AgCl}$ electrodes from 12 scalp locations of the 10-20 system, referenced to the left mastoid. Horizontal and vertical EOGs were recorded bipolarly. Sampling rate was $250 \mathrm{~Hz}$, EEG data were filtered off-line with a $20 \mathrm{~Hz}$ low-pass filter (1001 points, FIR) and re-referenced to the algebraically mean of the left and right mastoid electrodes (in order to guarantee that lateralization of effects is not due to the placement of a reference electrode). For elimination of artefacts, caused by eye or body movements, filtered EEG data were rejected off-line from the raw EEG whenever the standard deviation (a) within a 200-msec gliding window exceeded $60 \mu \mathrm{V}$ in the vertical and the horizontal electrooculogram, (b) within a 200-msec and a 600-msec gliding window exceeded $50 \mu \mathrm{V}$ at any electrode. Trials were averaged off-line from -200 to $1200 \mathrm{msec}$ with respect to stimulus onset, using a 200-msec prestimulus baseline.

Amplitude peaks of effects were determined in the difference signals (appropriate subtracted from inappropriate chords). For statistical analyses, two time windows were chosen around the amplitude peaks of effects: an early window of 150 msec length (280$430 \mathrm{msec}$ ), and a late window of $200 \mathrm{msec}$ length (500-700 msec).

ERPs were evaluated statistically by computing two regions of interest (ROIs): left anterior (F3, FC3, C3) and right anterior (F4, FC4, C4). Variances of ERPs were analyzed by repeated-measures ANOVAs. Analyzed factors were: Chord-type (in-key, transposed chords), Lateralization (left, right), Position (3rd, 5th), and Age (5, 9 years); all factors, thus, had two levels.

Because the sequences with deviant instruments were only employed to control whether the children actually listened to the music, and because the duration of the experimental session had to be kept as short as possible, only few trials with deviant instruments were 
presented, resulting in a low signal-to-noise ratio of the ERPs of deviant instruments. Thus, these ERPs were not further analyzed.

\section{Acknowledgments}

The work was supported by the Leibniz Science Prize awarded to A. D. Friederici by the German Research Foundation and by the German Academic Exchange Service (Deutscher Akademischer Austauschdienst, DAAD). The study was conducted at the Max-Planck-Institute of Cognitive Neuroscience, Leipzig, Germany.

Examples of the stimuli can be found at: www.stefan-koelsch.de.

Reprint requests should be sent to Stefan Koelsch, Max-PlanckInstitute of Cognitive Neuroscience, Stephanstr. 1a, 04103 Leipzig, Germany, or via e-mail: mail@stefan-koelsch.de.

\section{REFERENCES}

Allen, L., \& Gorski, R. (1991). Sexual dimorphism of the anterior commissure and massa intermedia in the human brain. Journal of Comparative Neurology, 312, 97-104.

Amunts, K., Schleicher, A., Burgel, U., Mohlberg, H., Uylings, H., \& Zilles, K. (1999). Broca's region revisited: Cytoarchitecture and intersubject variability. Journal of Comparative Neurology, 412, 319-341.

Basso, A., Bracci, M., Capitani, E., Laiacona, M., \& Zanobio, M. (1987). Age and evolution of language area functions: A study on adult stroke patients. Cortex, 23, 475-483.

Basso, A., \& Scarpa, T. (1990). Traumatic aphasia in children an adults: A comparison of clinical features and evolution. Cortex, 26, 501-514.

Bharucha, J., \& Krumhansl, C. (1983). The representation of harmonic structure in music: Hierarchies of stability as a function of context. Cognition, 13, 63-102.

Bharucha, J., \& Stoeckig, K. (1986). Reaction time and musical expectancy: Priming of chords. Journal of Experimental Psychology: Human Perception and Performance, 12, 403-410.

Bharucha, J., \& Stoeckig, K. (1987). Priming of chords: Spreading activation or over-lapping frequency spectra? Perception and Psychophysics, 41, 519-524.

Bigand, E., Madurell, F., Tillmann, B., \& Pineau, M. (1999). Effect of global structure and temporal organization on chord processing. Journal of Experimental Psychology: Human Perception and Performance, 25, 184-197.

Bigand, E., \& Pineau, M. (1997). Global context effects on musical expectancy. Perception and Psychophysics, 59, 1098-1107.

Bigand, E., Tillmann, B., Poulin, B., Adamo, D., \& Madurell, F. (2001). The effect of harmonic context on phoneme monitoring in vocal music. Cognition, 81, B11-B20.

Caplan, D., Alpert, N., \& Waters, G. (1999). PET-studies of syntactic processing with auditory sentence presentation. Neuroimage, 9, 343-351.

Caplan, D., Alpert, N., Waters, G., \& Olivieri, A. (2000). Activation of Broca's area by syntactic processing under condition of concurrent articulation. Human Brain Mapping, 9, 65-71.

Cheour, M., Leppänen, P., \& Kraus, N. (2000). Mismatch negativity (MMN) as a tool for investigating auditory discrimination and sensory memory in infants and children. Clinical Neurophysiology, 111, 4-16.

Curry, J., \& Polich, J. (1992). P300, global probability, and stimulus sequence effects in children. Developmental Neuropsychology, 8, 185-202.

Dapretto, M., \& Bookheimer, S. (1999). Form and content: Dissociating syntax and semantics in sentence comprehension. Neuron, 24, 427-432.

deLacoste Utamsing, M., \& Holloway, R. (1982). Sexual dimorphism in the human corpus callosum. Science, 216, $1431-1432$.

Deliège, C. (1984). Les fondements de la musique tonale. Paris: J.C. Lattès.

Dennis, M. (1980). Capacity and strategy for syntactic comprehension after left or right hemidecortication. Brain and Language, 10, 287-317.

Dennis, M., \& Kohn, B. (1975). Comprehension of syntax in infantile hemiplegics after cerebral hemidecortication: Left-hemisphere superiority. Brain and Language, 2, $472-482$.

Dennis, M., \& Whitaker, H. (1976). Language acquisition following hemidecortication: Linguistic superiority of the left over the right hemisphere. Brain and Language, 3, 404-433.

Ekstrand, L. H. (1980). Sex differences in second language learning? Empirical studies and a discussion of related findings. International Review of Applied Psychology, 29, 205-259.

Fernald, A. (1989). Intonation and communicative intent in mothers' speech to infants: Is the melody the message? Child Development, 60, 1497-1510.

Friederici, A. (1983). Children's sensitivity to function words during sentence comprehension. Linguistics, 21, 717-739.

Friederici, A. (1994). Funktionale organisation und reorganisation der sprache ẅahrend der sprachentwicklung. Neurolinguistik, 8, 41-55.

Friederici, A. (2002). Towards a neural basis of auditory sentence processing. Trends in Cognitive Science, 6, 78-84.

Friederici, A. D. (Ed.) (1998). Language comprehension: A biological perspective. Heidelberg: Springer.

Friederici, A. D., Meyer, M., \& von Cramon, D. Y. (2000). Auditory language comprehension: An event-related fMRI study on the processing of syntactic and lexical information. Brain and Language, 74, 289-300.

Friederici, A. D., Wang, Y., Herrmann, C., Maess, B., \& Oertel, U. (2000). Localisation of early syntactic processes in frontal and temporal cortical areas: An MEG study. Human Brain Mapping, 11, 1-11.

Fuchigami, T., Okubo, O., Fujita, Y., \& Okuni, M. (1993). Auditory event-related potentials and reaction time in children: Evaluation of cognitive development. Developmental Medicine and Child Neurology, 35, 230-237.

Gaillard, F., Converso, G., \& Ben Ammar, S. (1988). The longterm reliability of a dichotic digit-recall test: A longitudinal study of primary schoolchildren over 5 years. Cahiers de Psychologie Cognitive, 8, 27-37.

Gomot, M., Giard, M., Roux, S., Barthelemy, N., \& Bruneau, C. (2000). Maturation of frontal and temporal components of mismatch negativity (MMN) in children. NeuroReport, 11, 3109-3112.

Hahne, A., \& Friederici, A. (1999). Rule-application during language comprehension in the adult and the child. In A. Friederici \& R. Menzel (Eds.), Learning: Rule extraction and representation. New York: Walter de Gruyter.

Harasty, J., Double, K., Halliday, G., Kril, J., \& McRitchie, D. (1997). Language associated cortical regions are proportionally larger in the female brain. Archives of Neurology, 54, 171-176.

Hier, D. (1979). Sex differences in hemispheric specialization: Hypothesis for the excess of dyslexia in boys. Bulletin of the Orton Society, 29, 74-83. 
Hindemith, P. (1940). Unterweisung im Tonsatz, 1 Theoretischer Teil. Mainz: Schott.

Huron, D., \& Parncutt, R. (1993). An improved model of tonality perception incorporating pitch salience and echoic memory. Psychomusicology, 12, 154-171.

Inglis, J., \& Lawson, J. (1881). Sex differences in the effects of unilateral brain damage on intelligence. Science, 212, 693-695.

Jaeger, J., Lockwood, A., Van Valin, R., Kemmerer, D. L., Murphy, B., \& Wack, D. (1998). Sex differences in brain regions activated by grammatical and reading tasks. NeuroReport, 9, 2803-2807.

Jusczyk, P., Hirsh-Pasek, K., Kemler-Nelson, D., Kennedy, L., Woodward, A., \& Piwoz, J. (1992). Perception of acoustic correlates of major phrasal units by young infants. Cognitive Psychology, 24, 252-293.

Jusczyk, P. W., \& Krumhansl, C. L. (1993). Pitch and rhythmic patterns affecting infants' sensitivity to musical phrase structure. Journal of Experimental Psychology: Human Perception and Performance, 19, 627-640.

Kansaku, K., Yamaura, A., \& Kitazawa, S. (2000). Sex differences in lateralization revealed in the posterior language areas. Cerebral Cortex, 10, 866-872.

Kilpelainen, R., Koistinen, A., Kononen, M., Herrgard, E., \& Partanen, J. (1999). P300 sequence effects differ between children and adults for auditory stimuli. Psychophysiology, 36, 343-350.

Kimura, D. (1999). Sex and cognition. Cambridge: MIT Press.

Koelsch, S., Gunter, T., Friederici, A. D., \& Schröger, E. (2000) Brain indices of music processing: "non-musicians" are musical. Journal of Cognitive Neuroscience, 12, 520-541.

Koelsch, S., Gunter, T., Schröger, E., Tervaniemi, M., Sammler, D., \& Friederici, A. D. (2001). Differentiating ERAN and MMN: An ERP-study. NeuroReport, 12, 1385-1389.

Koelsch, S., Gunter, T., von Cramon, D. Y., Zysset, S., Lohmann, G., \& Friederici, A. D. (2002). Bach speaks: A cortical "language-network" serves the processing of music. Neuroimage, 17, 956-966.

Koelsch, S., Maess, B., \& Friederici, A. D. (2000). Musical syntax is processed in the area of Broca: An MEG study. Neuroimage, 11, 56.

Koelsch, S., Maess, B., Grossmann, T., \& Friederici, A. (2002). Sex difference in music-syntactic processing. NeuroReport, 14, 709-712.

Koelsch, S., Schmidt, B., \& Kansok, J. (2002). Influences of musical expertise on the ERAN: An ERP-study. Psychophysiology, 39, 657-663.

Koelsch, S., Schröger, E., \& Gunter, T. (2002). Music matters: Preattentive musicality of the human brain. Psychophysiology, 39, 1-11.

Kramer, J. H., Delis, D. C., \& Daniel, M. H. (1988). Sex differences in verbal learning. Journal of Clinical Psychology, 44, 907-915.

Kramer, J. H., Delis, D. C., Kaplan, E., O’Donnell, L., \& Prifitera, A. (1997). Developmental sex differences in verbal learning Neuropsychologia, 11, 577-584.

Kraus, N., McGee, T., Micco, A., Sharma, A., Carrell, T., \& Nicol, T. (1992). Mismatch negativity event-related potential elicited by speech stimuli. Ear and Hearing, 13, $158-164$

Krumhansl, C., Bharucha, J., \& Kessler, E. (1982). Perceived harmonic structure of chords in three related musical keys. Journal of Experimental Psychology: Human Perception and Performance, 8, 24-36.

Krumhansl, C., \& Kessler, E. (1982). Tracing the dynamic changes in perceived tonal organization in a spatial representation of musical keys. Psychological Review, 89, $334-368$
Krumhansl, C. L., \& Jusczyk, P. W. (1990). Infants' perception of phrase structure in music. Psychological Science, 1, 70-73.

Liegeois-Chauvel, C., Peretz, I., Babaie, M., Laguitton, V., \& Chauvel, P. (1998). Contribution of different cortical areas in the temporal lobes to music processing. Brain, 121, $1853-1867$.

Maess, B., Koelsch, S., Gunter, T., \& Friederici, A. D. (2001). "Musical syntax" is processed in the area of Broca: An MEG-study. Nature Neuroscience, 4, 540-545.

McGlone, J. (1980). Sex differences in human brain asymmetry: A critical survey. Behavioral and Brain Sciences, 3, $215-263$.

Moulden, J., \& Persinger, M. (2000). Delayed left ear accuracy during childhood and early adolescence as indicated by Roberts' dichotic word listening test. Perceptual Motor Skills, 90, 893-898.

Näätänen, R. (1992). Attention and brain function. Hillsdale, NJ: Erlbaum.

Papoušek, H. (1996). Musicality in infancy research. In J. Sloboda \& I. Deliege (Eds.), Musical beginnings. Oxford: Oxford University Press.

Parncutt, R. (1989). Harmony: A psychoacoustical approach. Berlin: Springer.

Parncutt, R., \& Bregman, A. (2000). Tone profiles following short chord progressions: Top-down or bottom-up? Music Perception, 18, 25-57.

Patel, A. D., Gibson, E., Ratner, J., Besson, M., \& Holcomb, P. (1998). Processing syntactic relations in language and music: An event-related potential study. Journal of Cognitive Neuroscience, 10, 717-733.

Peretz, I., Kolinsky, R., Tramo, M., \& Labrecque, R. (1994). Functional dissociations following bilateral lesions of auditory cortex. Brain, 117, 1283-1301.

Phillips, M., Lowe, M., Dzemidzic, M., \& Mathews, V. (2001). Temporal lobe activation demonstrates sex-based differences during passive listening. Radiology, 220, 202-207.

Piston, W. (1987). Harmony. New York: Norton

Platel, H., Price, C., Baron, J., Wise, R., Lambert, J., Frackowiak, R., Lechevalier, B., \& Eustache, F. (1997). The structural components of music perception, a functional anatomical study. Brain, 120, 229-243.

Pugh, K., Shaywitz, B., Shaywitz, S., Pugh, K., Constable, R., Skudlarski, P., Fulbright, R., Bronen, R., Shankweiler, D., Katz, L., Fletcher, J., \& Gore, J. (1996). Cerebral organization of component processes in reading. Brain, 119, 1221-1238.

Regnault, P., Bigand, E., \& Besson, M. (2001). Different brain mechanisms mediate sensitivity to sensory consonance and harmonic context: Evidence from auditory event-related brain potentials. Journal of Cognitive Neuroscience, 13, $241-255$.

Schmuckler, M. (1989). Expectations in music: Investigation of melodic and harmonic processes. Music Perception, 7, $109-150$

Schönberg, A. (1969). Structural functions of harmony (Rev. ed.). New York: Norton.

Schröger, E. (1998). Measurement and interpretation of the mismatch negativity (MMN). Behavior Research Methods, Instruments, and Computers, 30, 131-145.

Shaywitz, B., Shaywitz, S., Pugh, K., Constable, R., Skudlarski, P., Fulbright, R., Bronen, R., Fletcher, J., Shankweiler, D., Katz, L., \& Gore, J. (1995). Sex differences in the functional organization of the brain for language. Nature, 373, 607-609.

Sloboda, J. (1985). The musical mind: The cognitive psychology of music. New York: Oxford University Press.

Steinmetz, H., Staiger, J., Schlaug, G., Huang, Y., \& Jancke, L. (1995). Corpus callosum and brain volume in women and men. NeuroReport, 6, 1002-1004. 
Swain, J. (1997). Musical languages. United Kingdom: Norton.

Tillmann, B., Bharucha, J., \& Bigand, E. (2000). Implicit learning of tonality: A self-organized approach. Psychological Review, 107, 885-913.

Tillmann, B., Bigand, E., \& Madurell, F. (1998). Local versus global processing of harmonic cadences in the solution of musical puzzels. Psychological Research, 61, 157-174.

Tillmann, B., Bigand, E., \& Pineau, M. (1998). Effects of global and local contexts on harmonic expectancy. Music Perception, 16, 99-117.

Trainor, L., \& Trehub, S. (1992). A comparison of infants' and adults' sensitivity to western musical structure. Journal of Experimental Psychology: Human Perception and Performance, 18, 394-402.
Trehub, S., Schellenberg, G., \& Hill, D. (2000). The origins of music: Perception and cognition: A developmental perspective. In N. L. Wallin, B. Merker, \& S. Brown (Eds.), The origins of music. Cambridge: MIT Press.

Wallin, N. L., Merker, B., \& Brown, S. (Eds.) (2000). The origins of music. Cambridge: MIT Press.

Woods, B., \& Teuber, H. (1978). Changing patterns of childhood aphasia. Annals of Neurology, 3, 273-280.

Zatorre, R., Evans, A., \& Meyer, E. (1994). Neural mechanisms underlying melodic perception and memory for pitch. Journal of Neuroscience, 14, 1908-1919.

Zatorre, R., \& Peretz, I. (Eds.) (2001). The biological foundations of music. Annals of the New York Academy of Sciences, 930, ix. 